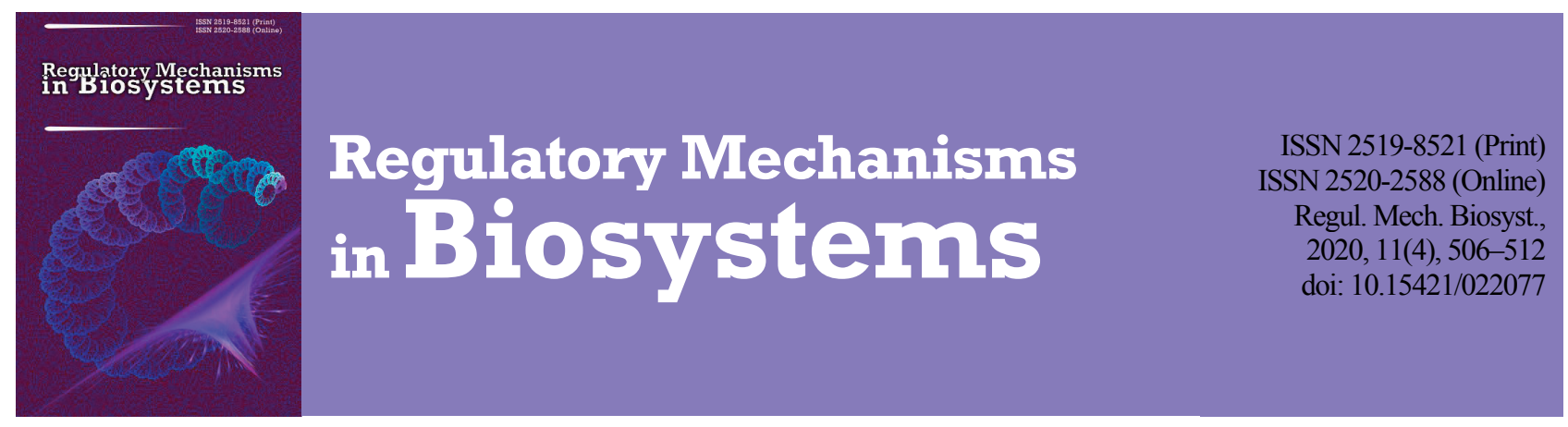

\title{
Immunogenicity and duration of immunity of the polyvalent vaccine against chicken salmonellosis
}

\author{
O. M. Sen*, O. O. Saliy***, V. I. Mazurkevych*****, Y. A. Sobko* \\ *"Biotestlab" Ltd., Kyiv, Ukraine \\ **Kyiv National University of Technologies and Design, Kyiv, Ukraine \\ ***National University of Life and Environmental Sciences of Ukraine, Kyiv, Ukraine
}

Article info

Received 15.11.2020

Received in revised form

10.12.2020

Accepted 11.12.2020

"Biotestlab" Ltd.,

Akademika Lebedeva st., 1 ,

Kyiv, 02000, Ukraine.

Tel.: +38-098-597-82-12.

E-mail:o_sen@biotestlab.net

Kyiv National University

of Technologies and Design,

Nemyrovycha-Danchenka st., 2 ,

Kyiv, 01011, Ukraine.

Tel.: +38-097-256-46-20

E-mail:e_saliy@biotestlab.net

National University of Life

and Environmental Sciences

of Ukraine, Potekhina st., 16/12,

Kyiv, 03127, Ukraine.

Tel.: +38-097-117-73-01.

E-mail:

v_mazurkevich@biotestlab.net

\begin{abstract}
Sen, O. M., Saliy, O. O., Mazurkevych, V. I., \& Sobko, Y. A. (2020). Immunogenicity and duration of immunity of the polyvalent vaccine against chicken salmonellosis. Regulatory Mechanisms in Biosystems, 11(4), 506-512. doi:10.15421/022077
\end{abstract}

Poultry salmonellosis causes serious economic damage and must be prevented by disinfection, zoohygienic measures or by vaccination. To develop a new polyvalent vaccine against poultry salmonellosis, we used bacterial strains of Salmonella enteritidis, S. typhimurium and S. gallinarum. Antigenic and immunogenic efficacy of the vaccine was tested on specific-pathogen free chickens, which were divided into five groups of 10 birds in each group and were vaccinated intramuscularly at 8 and 12 weeks: group A (non-immunized control), group B ( $S$. enteritidis mono-vaccine), group C (S. typhimurium mono-vaccine), group D (S. gallinarum mono-vaccine) and group E (trivalent vaccine Polimun Salmo). None of the immunized birds showed such adverse reactions as abnormal behaviour, mortality or signs of anorexia, depression or diarrhea. Two weeks after the revaccination, 5 birds in each group were challenged by watering $3 \mathrm{~cm}^{3}$ of working suspensions of $S$. gallinarum, S. typhimurium and $S$. enteritidis control strains at a concentration of $1 \times 10^{9} \mathrm{CFU} .72 \mathrm{~h}$ after the challenge, faeces were collected from all chickens in each group to identify Salmonella excretion with faeces, and the chickens were euthanized. Significant protection against the virulent challenge was observed in all immunized groups based on mortality and post-mortem lesions compared with the non-immunized control group. Blood samples were selected weekly from 5 chickens of each group for 184 days. The antigenic efficacy of the vaccines was studied by reaction of haemagglutination in the obtained serum. The potent antigen-specific response to lymphocyte activation found in all immunized groups indicated the induction of immune responses. Overall, the results showed that persistent immunity is formed in 4 weeks after the revaccination and lasts for a productive period. Immune response of chickens on day 184 after vaccination with Polimun Salmo was 1: 647, indicating that the developed polyvalent vaccine against common serovars of $S$. enterica in poultry is effective and immunogenic and can be further used in field studies.

Keywords: poultry; Salmonella, bacterial host; pathogenic activity of strains; postvaccinal response; reaction of agglutination.

\section{Introduction}

Poultry salmonellosis is a common disease caused by bacteria of the genus Salmonella. The economic impact of the infection cannot be overlooked, as it inflicts serious economic damage on both the private sector and the economy of the state as a whole. Due to the persistence of the bacteria in the environment and the rapid development of antibiotic resistance, the problem of human and animal diseases with salmonellosis has remained relevant during the last ten years. Despite the detailed study of salmonellosis pathogens, the definitive elimination of this disease is impossible. Also one of the factors in the problem of salmonellosis in the world is the transmission of the pathogen from sick birds to humans. As of August 2019, Centers for Disease Control and Prevention (USA) has registered 1003 people infected with Salmonella outbreak strains in 49 states, of which $23 \%$ were children under the age of 5. Epidemiologic and laboratory records indicate that contact with backyard poultry, such as chicks and ducklings, from multiple hatcheries were the likely source of these outbreaks (Centers for Disease Control and Prevention, 2019). The main source of this disease for humans is the meat of chickens, turkeys and pigs, as well as chicken eggs (Borges et al., 2017; Cheng et al., 2019).

The United States Department of Agriculture estimates the economic damage caused by foodborne infections is $\$ 3.13$ billion a year. The share of economic damage directly caused by salmonellosis is $\$ 2.56$ billion a year (Roos, 2010, Boore et al,. 2015). A European outbreak of salmonel- losis occurred in 2008 in the European Union. Salmonellosis ranked second after campylobacteriosis that year. From the entire list of Salmonella isolated during that period, the serovars of $S$. enteritidis and $S$. eyphimurium accounted for the largest share (Dragut, 2013; Anderson et al., 2016). The situation in Ukraine is also pushing for an effective way to prevent poultry salmonellosis. According to researchers from the Veterinary Diagnostic Center in the period 2014-2017 139 isolates of Salmonella spp. were isolated, 47 of which were in the Kyiv region.

The rapidly increasing number of antibiotic-resistant salmonella isolates found during research in food stresses the urgency of finding an effective way to prevent poultry salmonellosis. Isolates resistant to the beta-lactam antibiotics, fluorophenicols, aminoglycosides, tetracyclines, chloramphenicols have now been identified (Nair et al., 2018). The isolates found on the territory of Ukraine for the period of 2015-2017 are resistant to antibiotics such as flumequin, oxytetracycline, enrofloxacin, danofloxacin, tilmicosin (Nyzhnyk et al., 2018). At the state level, the problem of poultry salmonellosis occupies an important place, since the decree No 310 of 19.09.2016 by the Ministry of Agrarian Policy and Food of Ukraine approved the instruction on the prevention and elimination of poultry salmonellosis. It was found that in laying hens $S$. enteritidis is most commonly found, in broilers $-S$. typhimurium, in ducks, geese, pigeons - S. typhimurium (On approval of the instructions for the prevention and elimination of avian salmonellosis. Order of the Ministry of Agrarian Policy and Food of Ukraine No. 310 dated 19.09.2016). 
For the prevention of salmonellosis, in addition to antibiotic therapy, disinfection and improvement of the zoohygienic conditions of poultry, vaccines are used (Van Immerseel et al., 2005). But vaccination, especially on large farms, is an effective way to address human and avian salmonellosis. Immunization of chickens can reduce both horizontal and vertical transmission of salmonella pathogens (Young et al., 2007; Toyota-Hanatani et al., 2009). According to the analysis, vaccinated chickens have a lower prevalence of salmonella in the caecum $(38.3 \%$ vs. $64.2 \%$; $\mathrm{P}<$ $0.001)$ and genital system $(14.2 \%$ vs. $51.7 \% ; \mathrm{P}<0.001)$. A lower prevalence of Salmonella in broiler chickens $(18.1 \%$ vs. $33.5 \%$; $\mathrm{P}<0.001)$ obtained from vaccinated livestock (Dórea et al., 2010). Factors affecting the ability of Salmonella to infect particular birds, such as chickens, are complex and form the so-called "epizootic triangle" - susceptible animals, pathogens and external influences.

Most scientists agree that the major efforts to prevent salmonellosis should be directed to those serovars which pose the greatest danger to the bird and human body. These serovars for Europe are considered to be S. typhimurium and $S$. enteritidis, which have a wide range of susceptible organisms. S. enterica serovars such as S. typhi, S. dublin and S. gallinarum have a limited range in which they are associated with one or more animal species (Wigley et al., 2005; Foley et al., 2013; Wigley, 2017).

There is a constant search for ways to prevent contamination of flocks and, therefore, poultry products by Salmonella pathogens (El-Tayeb et al., 2017; Guo et al., 2017; Dos Santos et al., 2019). When developing a vaccine for chicken salmonellosis, the immune response is complex and involves the interaction of many components of the immune system (Jawale \& Lee, 2014; Jawale \& Lee, 2016; Lalsiamthara et al., 2016).

The range of registered vaccines against chicken salmonellosis on the Ukrainian market is represented by leading foreign manufacturers, and one domestic vaccine developed by the NEC "Institute for Experimental and Clinical Veterinary Medicine". Protection of poultry is due to the use of most inactivated vaccines, which are usually bivalent, containing as immunogens the serovars of $S$. typhimurium and $S$. enteritidis, protective determinants of $S$. enterica strain (Boyko et al., 2014). Also registered are SalmAbic Plus, Israel, which additionally introduced the $S$. infantis serovar and the Cevac SalmuneE TEK, USA, with the additional S. kentucky serovar. But available vaccines do not prevent typhoid (the main intracellular bacterial pathogen is the gram-negative bacterium $S$. enterica serovar gallinarum (S. gallinarum)) and septic disease of chickens, which is manifested in acute mortality, usually $60-70 \%$, and inflammation, typhlitis and omphalitis, and leads to significant economic losses for poultry (Matsuda et al., 2011, Chaudhari et al., 2012; Jawale \& Lee, 2016). Therefore, there is a need for polyvalent vaccines that can be safely administered to chickens (especially at a young age) to obtain required immune reactions and adequate protection against salmonellosis. Vaccines against Salmonella can act by various mechanisms. Inactivated vaccines are widely accepted in many countries for the vaccination of commercial table-egg layers. Most inactivated vaccines contain antigens and adjuvants with different levels of protection (Penha Filho et al., 2012). The recent development of novel adjuvant technology is very promising for the development of totally safe, inactivated Salmonella vaccines capable of inducing potent immune stimulation targeting different weapons of the chickens' immune system (Michell et al., 2009).

The objective of our research was to study the immunogenicity and duration of immunity of the developed inactivated vaccine Polimun Salmo by vaccinating specific pathogen free (SPF) chickens with monovalent vaccines, made from separate antigens, and multivalent vaccine, with subsequent challenge of vaccinated birds by virulent strains of Salmonella, and to study contamination of internal organs and formation of immunity response during 184 days.

\section{Materials and methods}

The bacterial strains of S. enteritidis, S. typhimurium and S. gallinarum were used to make the experimental vaccine batch. Strains were isolated from sick birds in the territory of Ukraine and characterized by the following methods: the compliance of the strains was confirmed by methods of polymerase chain reaction in real time. Culture type was determined according to the European Pharmacopeia 9.0 04/2013:1947 1,2,2-
1,3-1. The safety of veterinary vaccines and immunosera was evaluated (European Pharmacopoeia, 2007). The cultural and enzymatic properties of each strain were tested on media of meat-peptone agar (MPA, HiMedia Laboratories Pvt. Ltd, India) and xylose-deoxycholate lysine agar (XDL, HiMedia Laboratories Pvt. Ltd, India) according to European Pharmacopoeia 9.3. 04/2008: 5027 5.2.7. Evaluation of the efficacy of veterinary vaccines and immunosera (European Pharmacopoeia, 2007) was according to the following procedure: each strain was thawed separately, inoculated in the volume of $0.2 \mathrm{~cm}^{3}$ onto the surface of a Petri dish with agar. The inoculum was rolled out in a circular motion by tilting the cup. The plates were incubated at $35.0-37.0^{\circ} \mathrm{C}$ for 24 hours.

The antigenic structure of the strains was typed using salmonellosis $\mathrm{O}$-complex and monoreceptor $\mathrm{O}$ - and $\mathrm{H}$-agglutinating sera (manufacturer FCP "Kursk Biofactory" - "BIOK" company) in the agglutination reaction according to the "Guidelines for the use of polyvalent and monovalent Salmonella sera". The suspension was prepared by washing out microbial cells from Petri dishes with an approximate turbidity of 2 units on a McFarland scale, applied in an amount of $0.25 \mathrm{~cm}^{3}$ to a degreased slide and $0.25 \mathrm{~cm}^{3}$ of specific monovalent serum was added. The glasses were kept in a thermostat at $35-37^{\circ} \mathrm{C}$ for 10 minutes. The strain type was evaluated by the reaction of agglutination with $\mathrm{O}$ - and $\mathrm{H}$-agglutinating diagnostic sera.

Pathogenic activity of $S$. gallinarum SG-15, S. enteritidis SE-15, S. typhimurium ST-15 strains was tested on 5 chickens with status "Specific pathogen free" (further - SPF-chickens) at 8 weeks. To this end, the daily culture of $S$. enteritidis, $S$. typhimurium, $S$. gallinarum at a concentration of $10^{8}$ colony forming units (CFU) in $1 \mathrm{~cm}^{3}$ of suspension was applied by watering $3 \mathrm{~cm}^{3}$.

The chickens were observed daily for 14 days. From 1 day after infection and at least two times a week, samples of faeces were collected and sown to detect the content of Salmonella genus bacteria.

From chickens that died liver and spleen were obtained and sown on a XDL agar to detect Salmonella bacteria in the internal organs. After 14 days, the surviving chickens were euthanized.

Following the aseptic rules, the liver, spleen, heart blood, lungs, white and red muscles were sampled for bacteriological examination. The sampled organs were ground in a porcelain mortar using a selenite broth (HiMedia Laboratories Pvt. Ltd, India) in a ratio of 1:10, $0.2 \mathrm{~cm}^{3}$ of the resulting suspension was sown on Petri dishes with MPA and $0.2 \mathrm{~cm}^{3}$ on XDL agar. Selenite broth was transferred to sterile tubes, and the culture cups were incubated at $36.0 \pm 0.2^{\circ} \mathrm{C}$ for 12 hours, carried re-seeding from the selenite broth onto Petri dishes with XLD, the culture cups were incubated at $36.0 \pm 0.2^{\circ} \mathrm{C}$ for $16-18$ hours.

Working suspensions in the form of 1-billionth suspension of microbial bodies of Salmonella control (S. typhimurium, S. enteritidis, S. gallinarum) were grown on MPA at $37.0^{\circ} \mathrm{C}$ for 24 hours.

To assess the protective efficacy and induction of the immune response we used 8-week-old SPF chickens obtained from SPF chicken eggs, manufactured by VALO BioMedia, Germany. All the experimental work with the participation of the birds was carried out on the basis of the vivarium of BIOTESTLAB Ltd. The vivarium is equipped in accordance with sanitary and hygienic standards (temperature $19.0-24.0^{\circ} \mathrm{C}$, humidity not more than $50 \%$, in natural day-night light mode). During the experiment, the chicks of all groups were held in SPF boxes for isolated confinement. Conditions of keeping, feeding and watering conditions were the same for all groups of birds.

After the immunogenicity study of the vaccine, the studied birds were transferred to the vivarium of Biotestlab Ltd. where they were kept in the premises prepared for the study. Each group of animals was housed in separate cages, the animals were given a balanced feed and had free access to water and feed. All procedures with animals were performed in accordance with international rules and regulations of bioethics.

Monovaccines were prepared from S. typhimurium, S. enteritidis, $S$. gallinarum antigens, and a 3-antigen multivalent vaccine. The bacterial mass of each strain was accumulated separately on the nutrient medium for bacterial vaccines, incubation was performed for 24 hours at $37.0^{\circ} \mathrm{C}$. The cultures were inactivated by introducing formaldehyde at a rate of $0.2 \%$ of the formaldehyde final concentration to the volume of the culture in the initial stage of the stationary phase of its growth, followed by kee- 
ping at $37.0^{\circ} \mathrm{C}$ for 48 hours with constant stirring. For emulsification of concentrated Salmonella antigens, Twin-80 (Shenzhen RUIQI Industry Co., Ltd., China) was used as the surfactant, and mineral oil with the addition of Span- 80 was used as the oil base.

The concentration of microbial bodies of each strain in monovaccines and polyvalent vaccine was inactivated at a dose of: $S$. enteritidis not less than $10^{8} \mathrm{CFU}, S$. typhimurium not less than $10^{8} \mathrm{CFU}, S$. gallinarum not less than $10^{8}$ CFU. Manufactured experimental batches of monovalent and polyvalent vaccines against avian salmonellosis corresponded to quality control in terms of: sterility, harmlessness, antigenic efficiency, immunogenic efficiency, emulsion stability, residual amount of formaldehyde. Chickens with SPF status were divided into five groups (A, B, C, D, E) of 10 birds $(n=10)$ in each group with individual numbering. Each group was divided into two subgroups $(n=5)$ to study the antigen (I) and immunogenicity (II) of vaccine. The birds were immunized intramuscularly at a dose of $0.5 \mathrm{~cm}^{3}$. Group A - control, administered intramuscularly sterile solution of Phosphate Buffer Saline (PBS). Group B - vaccinated with $S$. enteritidis monovaccine (hereinafter SE-15), Group C vaccinated with $S$. typhimurium monovaccine (hereinafter ST-15), Group D - vaccinated with $S$. gallinarum monovaccine (hereinafter SG-15), Group E - vaccinated with 3-valent vaccine (hereinafter referred to as Polimun Salmo). Poultry revaccination in all studied groups was performed on the 28th day by a similar method at a dose of $0.5 \mathrm{~cm}^{3}$. After 14 days after revaccination, 5 chickens from groups of the second subgroup (II) were challenged by watering $3 \mathrm{~cm}^{3}$ of working suspensions of S. gallinarum, S. typhimurium and S. enteritidis control strains at a concentration of $1 \times 10^{9} \mathrm{CFU}$. The matrix of immunization and challenge of birds is presented in Table 1 .

\section{Table 1}

Matrix of immunization with monovalent and polyvalent vaccine and poultry challenge to determine immunogenic efficacy of the vaccine

\begin{tabular}{|c|c|c|c|c|c|c|c|}
\hline \multicolumn{2}{|c|}{$\begin{array}{c}\text { Groups of } \\
\text { studied birds }\end{array}$} & \multirow{2}{*}{$\begin{array}{c}\begin{array}{c}\text { Number } \\
\text { of poultry }\end{array} \\
5 \\
5\end{array}$} & \multirow{2}{*}{$\begin{array}{l}\text { Indicators of the study } \\
\text { study control } \\
\text { study control }\end{array}$} & \multirow{2}{*}{$\begin{array}{l}\text { Vaccination and revaccination on } 28 \text { day } \\
\text { intramuscular sterile PBS } 0.5 \mathrm{~cm}^{3}\end{array}$} & \multirow{2}{*}{$\begin{array}{l}\text { Study method } \\
\begin{array}{l}\text { blood sampling } \\
\text { challenge }\end{array}\end{array}$} & \multirow{2}{*}{$\begin{array}{c}\begin{array}{c}\text { Challenge dose, } \\
\text { CFU } / 3.0 \mathrm{~cm}^{3}\end{array} \\
1 \times 10^{9}\end{array}$} & \multirow{2}{*}{$\begin{array}{c}\text { Method } \\
\text { of challenge } \\
\text { oral }\end{array}$} \\
\hline A & $\begin{array}{l}\text { I } \\
\text { II }\end{array}$ & & & & & & \\
\hline B & $\begin{array}{l}\text { I } \\
\text { II }\end{array}$ & $\begin{array}{l}5 \\
5\end{array}$ & $\begin{array}{l}\text { antigenic efficacy } \\
\text { immunogenic efficacy }\end{array}$ & intramuscular S. enteritidis SE-15 & $\begin{array}{l}\text { blood sampling } \\
\text { challenge }\end{array}$ & $1 \times 10^{9}$ & oral \\
\hline $\mathrm{C}$ & $\begin{array}{l}\text { I } \\
\text { II }\end{array}$ & $\begin{array}{l}5 \\
5 \\
\end{array}$ & $\begin{array}{l}\text { antigenic efficacy } \\
\text { immunogenic efficacy }\end{array}$ & intramuscular S. typhimurium ST-15 & $\begin{array}{l}\text { blood sampling } \\
\text { challenge }\end{array}$ & $1 \times 10^{9}$ & oral \\
\hline $\mathrm{D}$ & $\begin{array}{l}\text { I } \\
\text { II }\end{array}$ & $\begin{array}{l}5 \\
5\end{array}$ & $\begin{array}{l}\text { antigenic efficacy } \\
\text { immunogenic efficacy }\end{array}$ & intramuscular $S$. gallinarum SG-15 & $\begin{array}{l}\text { blood sampling } \\
\text { challenge }\end{array}$ & $1 \times 10^{9}$ & oral \\
\hline $\mathrm{E}$ & $\begin{array}{l}\text { I } \\
\text { II }\end{array}$ & $\begin{array}{l}5 \\
5\end{array}$ & $\begin{array}{l}\text { antigenic efficacy } \\
\text { immunogenic efficacy }\end{array}$ & $\begin{array}{l}\text { intramuscular Polimun Salmo (S. enteritidis SE-15, } \\
\text { S. typhimurium ST-15, S. gallinarum SG-15) }\end{array}$ & $\begin{array}{l}\text { blood sampling } \\
\text { challenge }\end{array}$ & $1 \times 10^{9}$ & oral \\
\hline
\end{tabular}

To assess the antigenic efficacy of the vaccine, blood serum in the reaction of agglutination (RA) was examined. Blood samples were taken from chickens of the first subgroup (I) of each group and from 5 chickens of control group A on 7, 14, 21, 28, 42, 56, 70, 77, 85, 100, 120, 150, 170 and 184 days. Samples were taken from the wing vein of birds in the amount of $2.0-2.5 \mathrm{~cm}^{3}$ with sterile syringes with a volume of $5 \mathrm{~cm}^{3}$, and blood serum was obtained. Evaluation of the humoral immune response was performed in the RA. Inactivated bacterial cells of $S$. enteritidis, S. typhimurium, S. gallinarum monoantigens and polyantigen were used as antigens for RA, and serum immunoglobulins of vaccinated chickens were used as antibodies. HA was performed in polystyrene plates with a volume of $1.0 \mathrm{~cm}^{3}$. Serum was diluted with sterile saline in a ratio of $1: 10$ to $1: 1280$. To prepare the initial dilution $(1: 10), 0.9 \mathrm{~cm}^{3}$ of saline was added to the first well and added $0.1 \mathrm{~cm}^{3}$ of serum. In all subsequent wells $0.5 \mathrm{~cm}^{3}$ of saline was added. From the initial dilution, after thorough mixing, $0.5 \mathrm{~cm}^{3}$ was transferred to the second well and subsequent dilutions were made from 1:10 to 1:1280. The inactivated bacterial mass of the corresponding salmonella strains was diluted with saline to a concentration of 500 million microbial cells in $1.0 \mathrm{~cm}^{3}$. The prepared antigen was added by $0.5 \mathrm{~cm}^{3}$ to each well with serum and mixed thoroughly. Control antigen + saline. The plates were incubated in a thermostat at $37 \pm 1{ }^{\circ} \mathrm{C}$ for 18 hours. The results of antigenic efficacy were taken into account in the RA in sampled blood sera of subgroup (I). The reaction was considered positive if the suspension in the well became clear and the bacterial suspension formed in the form of an "open umbrella", indicating the presence of antibodies. The reaction was considered negative (absence of antibodies) if the precipitate of microbial cells at the bottom of the hole was collected in the form of a button, which when shaken, formed a homogeneous suspension.

$72 \mathrm{~h}$ after challenge with control strains, faecal samples were taken from all subgroup (II) chickens in each group to identify the excretion of Salmonella in the faeces, and the chickens were euthanized. Following aseptic rules, internal organs (liver, lungs, spleen, heart, kidneys, testicles, or ovaries) were sampled for bacteriological examination. Sampled organs and tissues were weighed, ground in a porcelain mortar with selenite broth in a ratio of 1:10. The resulting suspension of $0.2 \mathrm{~cm}^{3}$ was seeded on Petri dishes with MPA (one cup per material), in parallel, faecal masses were incubated in selenite broth. Petri dishes and selenite broth were incubated at $36.0 \pm 0.2^{\circ} \mathrm{C}$ for 12 hours. At the end of the incubation period, selenite broth was resuspended on Petri dishes with XLD agar and incubated at
$36.0 \pm 0.2{ }^{\circ} \mathrm{C}$ for $16-18$ hours. The results were recorded according to the number of CFU isolated from the organs and tissues of chickens after challenge with control strains of Salmonella. The typicality of the strains was evaluated by the results of the agglutination reaction with $\mathrm{O}-$ and $\mathrm{H}$ agglutinating diagnostic sera, as described above.

Statistical processing of the obtained results was performed with the calculation of the arithmetic mean (x) and the error of the arithmetic mean (m) using regression and correlation analyses in the ANOVA program, the difference was considered to be significant at $\mathrm{P}<0.05$ (taking into account the Bonferroni correction).

\section{Results}

The study of culture and enzymatic properties of the isolated strains showed that all three strains of S. gallinarum ST-15, S. typhimurium and S. enteritidis on MPA medium grew in the form of rounded colonies of greyish colour with a blue tinge, which is typical for bacteria of the Salmonella genus. On XLD medium, three strains grew in the form of red colonies with a black center. Gram-stained smear microscopy: $\mathrm{G}(-)$ rods, size $0.3-0.5 \times 0.9-2.5 \mu \mathrm{m}$, motile for $S$. typhimurium, S. enteritidis, and immobile for $S$. gallinarum.

Thus, it was found that the strain S. typhimurium ST-15 gave a positive reaction with O-sera - receptors: 1, 4, 5 and 12; with H-sera - receptors: i-1-phase; 1.2 -2-phase), which is characteristic of $S$. typhimurium bacteria. Strain $S$. enteritidis SE-15 gave a positive reaction with O-sera receptors: 1, 9 and 12; with H-sera - receptors: gm - 1-phase; 0 - 2-phase), which is characteristic of the bacteria $S$. enteritidis. Strain $S$. gallinarum SG15 gave a positive reaction with O-sera - receptors: 1,9 and 12; with $\mathrm{H}-$ sera - no antigen, which is characteristic of the bacteria S. gallinarum.

According to the results of determining the pathogenic properties of the strains, it was found that $100 \%$ of infected chickens died with signs characteristic of salmonellosis, in faeces, organ suspensions and on XLD agar there was growth typical for Salmonella (Table 3).

The results of determining the immunogenic efficacy of vaccines in subgroup II birds were taken into account by the indicator of the number of organs from which the culture of the control strain of salmonella was isolated in control and experimental chickens. According to the results of studies, cultures of control strains of Salmonella were not isolated from the organs and faecal masses of poultry of the experimental subgroups, in the control group S. gallinarum, S. typhimurium, S. enteritidis were isolated. 
Table 4 shows the results of bacteriological examination of organs and tissues of vaccinated chickens, on whom euthanasia was performed 72 hours after challenge with control strains of Salmonella.

According to our studies, a change in the colour of the XLD agar medium to black, characteristic of the growth of Salmonella cultures, was observed in Petri control plates. Seeding of faecal masses on XLD agar in experimental Petri dishes showed the growth of Escherichia coli bacteria (yellow colour of the medium) in groups of birds immunized with monovaccines (Fig. 1.). Sowing of suspensions of internal organs of the liver, spleen, kidneys and heart in experimental Petri dishes of the lower row showed no bacterial growth in groups of birds vaccinated with monovaccines S. typhimurium, S. gallinarum and polyvalent vaccine Polimun Salmo, where the colour of the medium remained red.

The results of immunity formation monitoring after vaccination and revaccination of poultry with monovalent vaccines and polyvalent vaccine Polimun Salmo are shown (Fig. 2). The titer of antibodies through the study period is shown to be higher and more stable in polyvalent vaccine due to cross immunity.

Table 2

The results of Salmonella strains typing by antigenic structure using Salmonella O-complex and monoreceptor O- and H-agglutinating sera

\begin{tabular}{|c|c|c|c|c|c|c|c|c|c|c|c|c|c|c|}
\hline \multirow[t]{2}{*}{ Strain } & \multirow{2}{*}{$\begin{array}{c}\text { Polyvalent } \\
\text { O-agglutinating serum }\end{array}$} & \multicolumn{5}{|c|}{ No. of monoreceptor O-antigenic complex serum } & \multicolumn{5}{|c|}{ Monoreceptor $\mathrm{H}$-antigens of phase 1} & \multicolumn{3}{|c|}{$\begin{array}{c}\text { Monoreceptor } \\
\text { H-antigens of phase } 2\end{array}$} \\
\hline & & 1 & 4 & 5 & 9 & 12 & $\mathrm{i}$ & $\mathrm{g}, \mathrm{p}$ & $\mathrm{d}$ & $\mathrm{gm}$ & $\mathrm{r}$ & 1.2 & 1.5 & $\mathrm{Z}_{6}$ \\
\hline S. enteritidis SE-15 & $++^{*}$ & + & $-{ }^{* *}$ & - & + & + & - & - & - & + & - & - & - & - \\
\hline S. typhimurium ST-15 & + & + & + & + & - & + & + & - & - & - & - & + & - & - \\
\hline S. gallinarum SG-15 & + & + & - & - & + & + & - & - & - & - & - & - & - & - \\
\hline
\end{tabular}

Notes: *-haemagglutination occurred; **-haemagglutination did not occur.

Table 3

The results of the study of pathogenic properties of Salmonella strains - S. typhimurium, S. enteritidis and S. gallinarum taking into account CFU ( \pm \pm SD)

\begin{tabular}{|c|c|c|c|c|c|c|c|c|c|c|c|c|}
\hline \multirow{3}{*}{$\begin{array}{c}\text { Organs and tissues } \\
\text { Medium }\end{array}$} & \multicolumn{6}{|c|}{ Organs of chickens on the 14th day after challenge } & \multicolumn{6}{|c|}{ Organs of chickens that died } \\
\hline & \multicolumn{2}{|c|}{ S. tphimurium } & \multicolumn{2}{|c|}{ S. enteritidis } & \multicolumn{2}{|c|}{ S. gallinarum } & \multicolumn{2}{|c|}{ S. typhimurium } & \multicolumn{2}{|c|}{ S. enteritidis } & \multicolumn{2}{|c|}{ S. gallinarum } \\
\hline & MPA* & XLD** & MPA & XLD & MPA & XLD & MPA & XLD & MPA & XLD & MPA & XLD \\
\hline White muscles & $8 \pm 2$ & $>300 \pm 15$ & $6 \pm 1$ & $>300 \pm 14$ & 0 & 0 & $>100 \pm 5$ & $>300 \pm 15$ & 0 & $>300 \pm 14$ & 0 & $>300 \pm 13$ \\
\hline Red muscles & $7 \pm 1$ & $>300 \pm 15$ & $3 \pm 1$ & $>300 \pm 16$ & 0 & 0 & $70 \pm 3$ & $>300 \pm 14$ & 1 & $>300 \pm 15$ & 0 & $>100 \pm 5$ \\
\hline Heart & $11 \pm 5$ & $>300 \pm 15$ & 0 & $>300 \pm 17$ & 0 & 0 & $6 \pm 1$ & $>300 \pm 16$ & $3 \pm 1$ & $>300 \pm 15$ & 0 & $>100 \pm 6$ \\
\hline Lungs & $9 \pm 4$ & $>300 \pm 15$ & 1 & $>300 \pm 16$ & 0 & 0 & $10 \pm 3$ & $>300 \pm 15$ & $5 \pm 1$ & $>300 \pm 14$ & 0 & $>100 \pm 5$ \\
\hline Liver & $216 \pm 10$ & $>300 \pm 15$ & $>300 \pm 15$ & $>300 \pm 14$ & 0 & 0 & $>300 \pm 14$ & $>300 \pm 16$ & 2 & $>300 \pm 15$ & 2 & $>300 \pm 15$ \\
\hline Spleen & $>300 \pm 15$ & $>300 \pm 14$ & $22 \pm 3$ & $>300 \pm 13$ & 0 & 0 & $>300 \pm 15$ & $>300 \pm 16$ & $>300 \pm 15$ & $>300 \pm 14$ & 1 & $>300 \pm 15$ \\
\hline Kidneys & $77 \pm 4$ & $>300 \pm 15$ & $4 \pm 1$ & $>300 \pm 16$ & 0 & 0 & $110 \pm 5$ & $>300 \pm 15$ & $6 \pm 1$ & $>300 \pm 15$ & $7 \pm 2$ & $>100 \pm 5$ \\
\hline Intestine & $>300 \pm 15$ & $>300 \pm 15$ & $>300 \pm 16$ & $>300 \pm 16$ & $10 \pm 5$ & $12 \pm 5$ & $>300 \pm 15$ & $>300 \pm 14$ & $>300 \pm 15$ & $>300 \pm 16$ & $>300 \pm 15$ & $>300 \pm 15$ \\
\hline
\end{tabular}

Notes: $*$-xylose-deoxycholate lysine agar, $* *$-media of meat-peptone agar.

Table 4

The results of bacteriological examination of organs and tissues of vaccinated chickens 72 hours after infection with control strains of Salmonella $(\mathrm{n}=5)$

\begin{tabular}{|c|c|c|c|c|c|c|c|c|c|c|}
\hline Organs and tissues & \multicolumn{2}{|c|}{ Control group (PBS) } & \multicolumn{2}{|c|}{ Monovaccine $S$. gallinarum } & \multicolumn{2}{|c|}{ Monovaccine S. typhimurium } & \multicolumn{2}{|c|}{ Monovaccine $S$. enteritidis } & \multicolumn{2}{|c|}{ Polimun Salmo } \\
\hline Medium & $\mathrm{XLD} * * *$ & $\mathrm{SB}^{* * * *}$ & XLD & SB & XLD & SB & XLD & SB & XLD & SB \\
\hline Heart & $0^{*}$ & 0 & 0 & 0 & 0 & 0 & 0 & 0 & 0 & 0 \\
\hline Lungs & 0 & 0 & 0 & 0 & 0 & 0 & 0 & 0 & 0 & 0 \\
\hline Liver & Salmonella growth & Salmonella growth & 0 & 0 & 0 & 0 & 0 & 0 & 0 & 0 \\
\hline Spleen & Salmonella growth & Salmonella growth & 0 & 0 & 0 & 0 & 0 & 0 & 0 & 0 \\
\hline Kidneys & Salmonella growth & Salmonella growth & 0 & 0 & 0 & 0 & 0 & 0 & 0 & BECG \\
\hline Ovaries & Salmonella growth & Salmonella growth & $\mathrm{BECG}^{* *}$ & BECG & 0 & BECG & BECG & BECG & 0 & BECG \\
\hline Faeces & Salmonella growth & Salmonella growth & BECG & BECG & 0 & BECG & BECG & BECG & 0 & 0 \\
\hline
\end{tabular}

Notes: * 0 - no growth; ** - BECG-bacteria of the Escherichia coli genus; $* * *$ - xylose-deoxycholate lysine agar; **** - selenite broth; Presented values are values \pm standard errors among 5 samples from each organ.

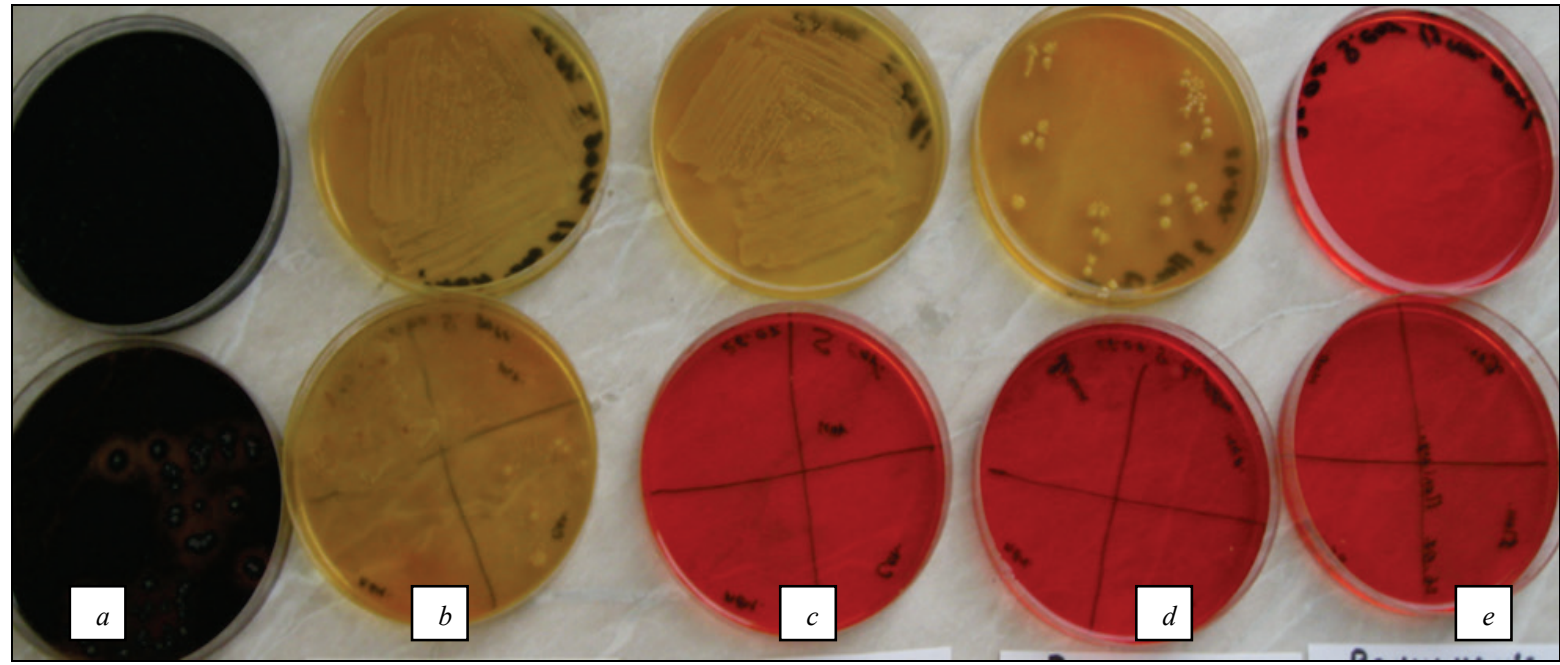

Fig. 1. Results of bacteriological studies of organs and tissues of vaccinated chickens and chickens of control group:

$a$-Group A (Control group); $b$ - Group B - immunization with monovaccine S. enteritidis SE-15; $c$ - Group C-immunization with monovaccine S. typhimurium ST-15; $d$-Group D - immunization with monovaccine $S$. gallinarum SG-15; $e$-Group E-immunization with vaccine Polimun Salmo 

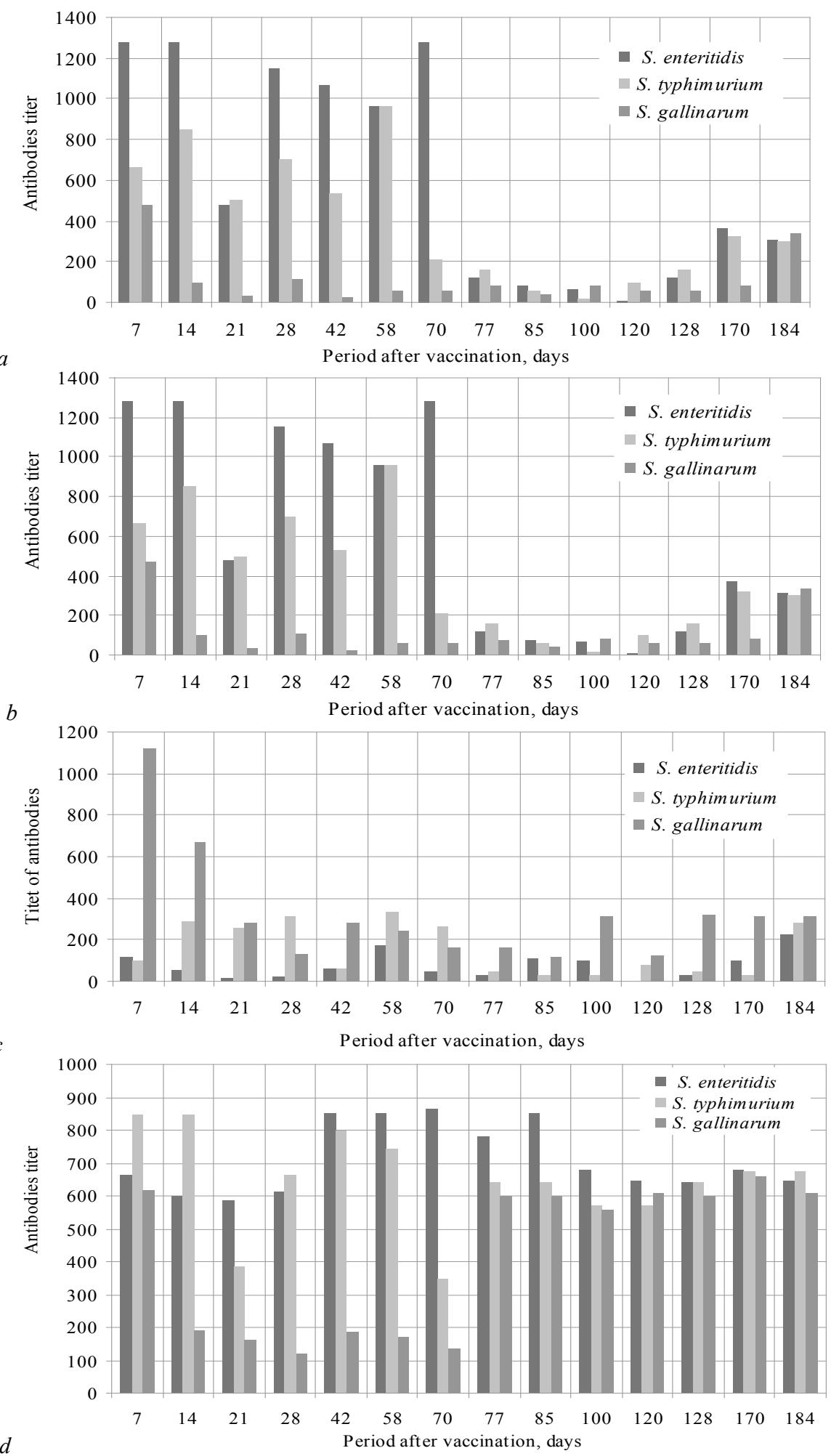

Fig. 2. Dynamics of avian immunity formation after vaccination with S. enteritidis (a), S. typhimurium (b), S. gallinarum (c) monovalent vaccines and polyvalent vaccine Polimun Salmo $(d)$

The immune response of chickens at 184 days after vaccination with monovaccines for S. enteritidis was 1:310, for S. typhimumum is 1:310, for S. gallinarum - 1:225. Immune response of chickens vaccinated with Polimun Salmo on day 184 after vaccination was 1:647, which gives reason to consider that the trivalent vaccine will form a stable immunity throughout whole production period of the chicken.

\section{Discussion}

Avian salmonellosis is caused by a large group (over 200 serotypes) of microorganisms. A study of the structure of bacterial diseases of agri- cultural, wild and ornamental birds in eastern Ukraine found that about $10 \%$ of all bacterial diseases of poultry are salmonellosis, three quarters of which are caused by Salmonella serotypes that are pathogenic not only to farm animals, birds and poultry but also to humans - S. enteritidis (45\%), S. typhimurium (30\%). Host-adapted serovars (S. gallinarum, S. pullorum) caused no more than $25 \%$ of cases. It has been found that avian salmonellosis vaccines should contain protective antigens that would stimulate the formation of protective antibodies against the above-mentioned salmonella serotypes (Trockyi, 2012). There were also found patterns in the manifestation of virulence and antigenic properties of the studied strains of Salmonella, namely, the higher the virulence of the strain, the higher its 
antigenic activity (Boiko et al., 2017). To develop vaccines against salmonellosis of poultry, socially important strains of Salmonella which most often cause food poisoning are chosen, such as S. typhimurium, S. enteritidis and S. gallinarum (Nair et al., 2018; Cao et al., 2019).

In this study, we developed a polyvalent vaccine against salmonellosis and evaluated its protective efficacy in chickens from strains isolated from sick birds in Ukraine. To identify and identify salmonella, conventional methods were used, which included selective enrichment and seeding followed by biochemical tests. Although the methods are time consuming, as they only give predictable results in 3-4 days and final results in 5-6 days, the interpretation of results, sufficient sensitivity and specificity of these methods allow us to reliably establish the culture and enzymatic properties of each strain. Rapid detection methods, such as DNA or RNA probing, immunodetection methods, and nucleic acid hybridization, do not yet have sufficient sensitivity and specificity (Ibrahim et al., 2016). The strains selected by us are virulent and immunogenic. After challenge by feeding $3 \mathrm{~cm}^{3}$ of microbial mass of at least $1 \times 10^{9} \mathrm{CFU}$ of each strain, in the birds of the control group on the second day we observed typical clinical signs of acute salmonellosis infection: depression, refusal to feed, debilitating diarrhea, fever, death. 100\% of infected SPF chickens (at least $80 \%$ of the criteria) died with signs typical for salmonellosis. In the sampled faeces, organ suspensions on XLD agar medium, the growth typical for Salmonella, was observed. Due to the active immunity acquired as a result of vaccination of chickens with the vaccine Polimun Salmo, for the next 72 hours, three strains of salmonella were eliminated from all organs and tissues. The results show that the higher the level of antibodies to both homologous and heterologous strains of salmonella, the higher the immune resistance to challenge with strains of Salmonella, the higher the specific resistance of vaccinated chickens to the salmonellosis pathogen.

Salmonellosis, like many other enteropathogenic bacteria, has evolved using a variety of virulence markers and other cellular mechanisms to colonize the host by attaching, invading, and bypassing the host's gastrointestinal defense mechanisms. These factors included flagella, capsules, plasmids, adhesion systems, etc. (Legba et al., 2020). Polimun Salmo vaccine developed from Salmonella strains containing immunogenic proteins of the outer membrane of S. gallinarum SG-15 and strains having F-proteins (flagella) and surface PNP lipids of S. typhimurium ST-15 and S. enteritiditis in the structure of the microbial cell 15 . The bacterial mass of each strain was converted into protective antigens of formalinized and concentrated cultures of $S$. enteritidis, S. typhimurium and $S$. gallinarum with a concentration of each antigen of at least 8 billion microbial bodies in a single dose (El-Safty et al., 2017). Observations of the birds after vaccination showed that none of the immunized animals showed any adverse reactions such as abnormal behaviour, mortality, or signs of anorexia, depression, or diarrhea. The polyvalent vaccine stimulated the formation of agglutinins in titers of at least 1:647. Significant protection against infection of internal organs and tissues with the introduction of ten DLm control strains was observed in all immunized groups on the basis of mortality and post-mortem lesions compared to the non-immunized control group. The final antibody titer in RA was considered with clear agglutination by 2 crosses $(++)$, and in the previous wells by clear agglutination by 4 and 3 crosses $(\mathrm{H}+\mathrm{H}$ or $\mathrm{H}+$ ). As the protective titer of antibodies in the body a titer of 1:160 is considered as sufficient for the body's immune response to a bacterial factor.

In a study of antigenic efficacy, all vaccinated groups, with both mono- and polyvalent vaccines, showed a significant increase in antibody titers compared to unvaccinated chickens. The strains used of S. typhimurium, $S$. enteritidis and $S$. gallinarum, which were part of the vaccine Polimun Salmo, showed virulence and immunogenic properties, and caused protective immunity. It was confirmed that with intramuscular vaccination of SPF chickens at a dose of $0.5 \mathrm{~cm}^{3}$ and subsequent revaccination on day 28 at a dose of $0.5 \mathrm{~cm}^{3}$, the level of antibodies in the serum of vaccinated chickens at $7,14,21,28,42,56,70,77,85,100,120,150,170$ and 184 days after revaccination allowed the dynamics of immune formation to be determined. A lower level of protection was observed when vaccinating chickens with mono vaccines from Salmonella strains. Intramuscular vaccination with Polimun Salmo and subsequent revaccination provided sustained protection against colonization and invasion. Revaccination significantly stimulated the formation of antibodies in the organism of vaccinated chickens. Stable immunity is formed in 4 weeks after revaccination and lasts for a productive period. The immune response of chickens on day 184 after revaccination was 1:647, vaccinated with monovaccine $S$. enteritidis on day 184 after revaccination was 1:310, vaccinated with monovaccine $S$. typhimunum on day 184 after revaccination was 1:310, vaccinated with $S$. gallinarum monovaccine on 184 day after revaccination was 1:225. Because S. typhimurium is an intracellular pathogen and mainly targets the intestinal tract, mucosal immunity with an antibody profile is likely to be involved in protection against microorganisms (Park et al., 2010; Jawale \& Lee, 2016), which explains the profile of formation of immunity after vaccination and revaccination of poultry with monovalent vaccine S. typhimurium (Liu et al., 2016). The vaccination protocol focuses on the production of broilers that are treated as table birds at 8 weeks of age, breeding and egg-laying birds. Immunity to salmonellosis has been studied and generalized (Penha Filho et al., 2012), but it is important to study the acquired immunity formed with the use of vaccines from strains isolated from sick birds in Ukraine. The study demonstrates that vaccination of chickens with Polimun Salmo vaccine is a safe approach to the prevention of avian salmonellosis without causing adverse clinical symptoms.

\section{Conclusion}

A combined vaccine was developed for common $S$. enterica poultry serovars, and the immunogenicity and duration of immunity of the polyvalent vaccine against salmonellosis in chickens was studied. Selected strains of Salmonella showed high virulence (invasive) properties in intact chickens, strains were deposited as controls to test the immunogenicity of Salmonella vaccines. The developed vaccine Polimun Salmo contains formalin-inactivated antigens of concentrated cultures of $S$. enteritidis, S. typhimurium and S. gallinarum with a concentration of each antigen of at least 8 billion microbial bodies in a single dose. The vaccine stimulates the formation of agglutinins in titers of at least 1:647 and provides protection against infection of the internal organs and tissues of the immunized bird, provided that ten DLm control strains are introduced. It was found that the vaccine Polimun Salmo forms the level of specific antibodies in the blood of birds from the 14th day after the second injection and remains stable at this level until the 184th day of observation, i.e. the bird retains a high rate of immune response. The level of antibodies is more pronounced in chickens that have been vaccinated with Polimun Salmo compared to chickens vaccinated with mono vaccines from strains of $S$. enteritidis, S. typhimurium and S. gallinarum. We believe that the higher the level of antibodies to both homologous and heterologous Salmonella strains, the higher the immune resistance to infection with control strains of Salmonella, the higher the specific resistance of vaccinated chickens to the salmonellosis pathogen. The obtained results state that the developed polyvalent vaccine against pathogens of common serovars of $S$. enterica poultry is effective and immunogenic and can be further studied in the field.

\section{References}

Anderson, T. C., Nguyen, T. A., Adams, J. K., Garrett, N. M., Bopp, C. A., Baker, J. B., McNeil, C., Torres, P., Ettestad, P. J., Erdman, M. M., Brinson, D. L., Gomez, T. M., \& Behravesh, C. B. (2016). Multistate outbreak of human Salmonella typhimurium infections linked to live poultry from agricultural feed stores and mail-order hatcheries, United States 2013. One Health, 2(1), 144-149.

Boiko, O. P., Sen, O. M., Boiko, P. K., Kurtiak, B. M., Pundiak, T. O., \& Sobko, G. V. (2017). Kharakterystyka morfolohichnykh oznak ta fiziolohichnykh vlastyvostey shtamiv sal'monel, izol'ovanykh vid ptytsi i telyat [Characteristics of morphological signs and physiological properties of salmonella strains, isolated from birds and calves]. Scientific Messenger of Lviv National University of Veterinary Medicine and Biotechnology, 78, 129-135 (in Ukrainian).

Boore, A. L., Hoekstra, R. M., Iwamoto, M., Fields, P. I., Bishop, R. D., \& Swerdlow, D. L. (2015). Salmonella enterica infections in the United States and assessment of coefficients of variation: A novel approach to identify epidemiologic characteristics of individual serotypes, 1996-2011. PLoS One, 10(12), 0145416.

Borges, K. A., Furian, T. Q., NevesShow, S., \& Pinheiro, V. (2017). Spread of a major clone of Salmonella enterica serotype enteritidis in poultry and in salmonellosis outbreaks in Southem Brazil. Journal of Food Protection, 80(1), 158-163.

Boyko, P. K., Kurtiak, B. M., Sen, O. M., Pundyak, T. O., \& Sobko, G. V. (2014). Osoblyvosti kontrolyu epizootychnoho protsesu za sal'monel'ozu ptytsi u ptak- 
hivnychykh hospodarstvakh Ukrayiny [Features of epizootic process control at avian salmonellosis in poultry farms of Ukraine. Scientific Messenger of Lviv National University of Veterinary Medicine and Biotechnology, 16(3), 58-64.

Cao, C., Zhang, Y., Zhang, Q., Xiao, Y., Zhao, R., Liu, C., Yang, H., Zhao, M., \& Yang, B. (2019). Characterization of Salmonella isolates recovered from processing chicken, retail chicken and chicken processing environment in Zhejiang and Shanghai. Food Science, 31(7), 1161-1169.

Chaudhari, A. A., Jawale, C. V., \& Kim, S. W. (2012). Construction of a Salmonella gallinarum ghost as a novel inactivated vaccine candidate and its protective efficacy against fowl typhoid in chickens. Veterinary Research, 43(44), 1-11.

Cheng, R. A., Eade, C. R., \& Wiedmann, M. (2019). Embracing diversity: Differences in virulence mechanisms, disease severity, and host adaptations contribute to the success of nontyphoidal Salmonella as a foodborne pathogen. Frontiers in Microbiology, 10, 1368.

Dórea, F. C., Cole, D. J., Hofacre, C., Zamperini, K., Mathis, D., Doyle, M. P., Lee, M. D., \& Maurer, J. J. (2010). Effect of Salmonella vaccination of breeder chickens on contamination of broiler chicken carcasses in integrated poultry operations. Applied and Environmental Microbiology, 76(23), 7820-7825.

Dos Santos, A. M. P., Ferrari, R. G., \& Conte-Junior, C. A. (2019). Virulence factors in Salmonella typhimurium: The sagacity of a bacterium. Current Microbiology, $76,762-773$

Dragut, S. S. (2013). Rozpovsyudzhennya sal'monel'ozu, kampilobakteriozu ta iyersy'niozu v Ukrayini ta krayinax YeS [The spread of salmonellosis, campylobacteriosis and yersiniosis in Ukraine and the EU countries]. Veterinary Medicine, 97, 186-188 (in Ukrainian).

El-Safty, M. M., Mahmoud, H., Zaki, E. A., \& Abd-Alla, H. I. (2017). Preparation and evaluation of chemically inactivated Salmonella enteritidis vaccine in chickens. Asian Journal of Pharmaceutical and Clinical Research, 10(11), 341-346.

El-Tayeb, M. A., Ibrahim, A. S. S., Al-Salamah, A. A., Almaary, K. S., \& Elbadawi, Y. B. (2017). Prevalence, serotyping and antimicrobials resistance mechanism of Salmonella enterica isolated from clinical and environmental samples in Saudi Arabia. Brazilian Journal of Microbiology, 48(3), 499-508.

Foley, S. L., Johnson, T. J., Ricke, S. C., Nayak, R., \& Danzeisenb, J. (2013). Salmonella pathogenicity and host adaptation in chicken-associated serovars. Microbiology and Molecular Biology, 77(4), 582-607.

Guo, R, Jiao, Y, Li, Z., Zhu, S., Fei, X., Geng, S., Pan, Z., Chen, X., Li, Q., \& Jiao, X. (2017). Safety, protective immunity, and DIVA capability of a rough mutant Salmonella pullorum vaccine candidate in broilers. Frontiers in Microbiology, $8,547$.

Ibrahim, H. M., Abd El-Moaty, D. A. M., Ahmed, H. A., \& El-Enbaawy, M. I. (2016). Phenotypic and genotypic characterization of locally isolated Salmonella strains used in preparation of Salmonella antigens in Egypt. Veterinary World, 9(12), 1435-1439.

Jawale, C. V., \& Lee, J. H. (2014). Characterization of a Salmonella typhimurium ghost carrying an adjuvant protein as a vaccine candidate for the protection of chickens against virulent challenge. Avian Pathology, 43(6), 506-513.

Jawale, C. V., \& Lee, J. H. (2016). Evaluation of immunogenicity and protective efficacy of adjuvanted Salmonella typhimurium ghost vaccine against salmonellosis in chickens. Veterinary Quarterly, 36(3), 130-136.

Lalsiamthara, J., Kamble, N. M., \& Lee, J. H. (2016). A live attenuated Salmonella enteritidis secreting detoxified heat labile toxin enhances mucosal immunity and confers protection against wild-type challenge in chickens. Veterinary Research, 47,60 .

Legba, B., Dougnon,V., Chabi, Y., Gbaguidi, C., Aniambossou, A., Deguenon, E., Dougnon, J., Kpodekon, M., \& Baba-Moussa, L. (2020). Evaluation of in-vivo anti-Salmonella activity of Uvaria chamae, Lantana camara and Phyllantus amarus used in Benin, West Africa. Veterinary Research, 16, 49.

Liu, Q., Liu, Q., Zhao, X., Liu, T., Yi, J., Liang, K., \& Kong, Q. (2016). Immunogenicity and cross-protective efficacy induced by outer membrane proteins from Salmonella typhimurium mutants with truncated LPS in mice. International Journal of Molecular Sciences, 17(3), 416.

Matsuda, K., Chaudhari, A. A., \& Lee, J. H. (2011). Evaluation of safety and protection efficacy on cpxR and lon deleted mutant of Salmonella gallinarum as a live vaccine candidate for fowl typhoid. Vaccine, 29(4), 668-674.

Michell, B. C., Gomes, A. D., Baião, N. C., Resende, M., Lara, L. J. C., \& Martins, N. R. S. (2009). Effect of maternally-derived antibodies on the performance and immunity of broilers induced by in ovo or post-hatching immunizations with a live vaccine against infectious bursal disease. Brazilian Joumal of Poultry Science, 11(1), 57-63.

Nair, D. V. T., Venkitanarayanan, K., \& Johny, A. K. (2018). Antibiotic-resistant Salmonella in the food supply and the potential role of antibiotic alternatives for control. Foods, 7(10), 167.

Park, S. I., Jeong, J. H., Choy, H. E., Rhee, J. H., Na, H. S., Lee, T. H., Her, M., Cho, K. O., \& Hong, Y. (2010). Immune response induced by ppGpp-defective Salmonella enterica serovar gallinarum in chickens. The Journal of Microbiology, 48(5), 674-681.

Penha Filho, R. A. C., Moura, B. S., de Almeida, A. M., Mon-tassier, H. J., Barrow, P. A., \& Berchieri, A. (2012). Humoral and cellular immune response generated by different vaccine programs before and after Salmonella enteritidis challenge in chickens. Vaccine, 30(52), 7637-7643.

Toyota-Hanatani, Y., Ekawa, T., Ohta, H., Igimi, S., Hara-Kudo, Y., Sasai, K., \& Baba, E. (2009). Public health assessment of Salmonella enterica serovar enteritidis inactivated-vaccine treatment in layer flocks. Applied and Environmental Microbiology, 75, 1005-1010.

Trockyi, M. S. (2012). Bird salmonellosis is the main cause of human salmonellosis. Livestock Today, 2, 34-37.

Van Immerseel, F., Methner, U., Rychlik, I., Nagy, B., Velge, P., Martin, G., Foster, N., Ducatelle, R., \& Barrow, P. A. (2005). Vaccination and early protection against non-host-specific Salmonella serotypes in poultry: Exploitation of innate immunity and microbial activity. Epidemiology and Infection, 133(6), 959-978.

Wigley, P. (2017). Salmonella enterica serovar gallinarum: Addressing fundamental questions in bacteriology sixty years on from the $9 \mathrm{R}$ vaccine. Avian Pathology, 30, $1-6$.

Wigley, P., Hulme, S., Powers, C., Beal, R., Smith, A., \& Barrow, P. (2005). Oral infection with the Salmonella enterica serovar gallinarum 9R attenuated live vaccine as a model to characterize immunity to fowl typhoid in the chicken. BMC Veterinary Research, 1,2.

Young, S. D., Olusanya, O., Jones, K. H., Liu, T., Liljebjelke, K. A., \& Hofacre, C. L. (2007). Salmonella incidence in broilers from breeders vaccinated with live and killed Salmonella. Journal of Applied Poultry Research, 16(4), 521-528. 